\title{
STUDI KINERJA KOMPON KARET ALAM TANPA BAHAN PENGISI SEBAGAI BAHAN PEMODIFIKASI ASPAL PANAS
}

\author{
Study on the Performance of Unfilled Natural Rubber Compound as \\ Modifier for Hot Asphalt \\ Henry PRASTANTO ${ }^{1 *}$, Yusef FIRDAUS ${ }^{2}$, Santi PUSPITASARI ${ }^{1}$, \\ Arief RAMADHAN ${ }^{1}$, dan Asron Ferdian FALAAH ${ }^{1}$ \\ ${ }^{1}$ Pusat Penelitian Karet \\ Jalan Salak Nomor 1 Bogor 16151 Jawa Barat \\ *Email : hprastanto@yahoo.com \\ ${ }^{2}$ Balai Bahan dan Perkerasan Jalan, Puslitbang Jalan dan Jembatan \\ Jalan AH Nasution Nomor 264 Ujung Berung Bandung 40294 Jawa Barat
}

Diterima : 14 Agustus 2018 / Disetujui : 5 November 2018

\begin{abstract}
Natural rubber is highly potencial to be used as polimer modified asphalt additive. This research studied the addition of natural rubber compound based on SIR 20 at concentration 3\%, 5\%, 7\%, and 9\% into asphalt pen 60 at $150^{\circ} \mathrm{C}$ in the production of rubberized asphalt. Agitation speed of the mixer was varied at $1000 \mathrm{rpm}, 2000 \mathrm{rpm}$, $4000 \mathrm{rpm}, 6000 \mathrm{rpm}, 8000 \mathrm{rpm}$, dan 10000 rpm. Natural rubber compounds were formulated based on the vulcanzation system ie conventional (KP1) and semi efficient (KP2). The observation proofed that the optimum agitation speed was at $6000 \mathrm{rpm}$. Further, based on the physical properties of rubberized asphalt characterization, it was found that 57\% natural rubber compound obtained from semi efficient vulcanization system (KP2) produced high quality rubberized asphalt. The quality was shown by the reduction of penetration which was followed by the raise of softening point, penetration index, elastic recovery, and good stability during storage and reheating of the rubberized asphalt.
\end{abstract}

Keywords : Natural rubber compound SIR 20; penetration; rubberized asphalt; softening point; vulcanization

\begin{abstract}
Abstrak
Karet alam berpotensi digunakan sebagai bahan aditif dalam pembuatan aspal modifikasi polimer. Dalam penelitian ini telah diujicobakan penambahan kompon karet alam berbasis karet SIR 20 pada konsentrasi 3\%, 5\%,7\% dan 9\% dalam aspal penetrasi 60 pada suhu $150^{\circ} \mathrm{C}$ sebagai upaya dalam pembuatan aspal karet. Sedangkan kecepatan pengaduk pada mesin pencampurkan divariasikan pada $1000 \mathrm{rpm}$, $2000 \mathrm{rpm}, 4000 \mathrm{rpm}, 6000 \mathrm{rpm}, 8000 \mathrm{rpm}$, dan 10000 rpm. Kompon karet SIR diformulasikan berdasarkan sistem vulkanisasi yaitu konvensional (KP1) dan semi effisien (KP2). Penilaian mutu aspal karet ditentukan berdasarkan pengujian sifat fisik aspal karet tersebut. Berdasarkan hasil pengamatan diketahui bahwa kecepatan pengaduk pada mesin pencampur aspal karet yang teroptimal sebesar $6000 \mathrm{rpm}$. Selanjutnya menurut hasil karakterisasi sifat fisik aspal karet diperoleh bahwa kompon karet SIR 20 yang dihasilkan dari sistem vulkanisasi semi effisien (KP2) dengan dosis 5-7\% dapat membentuk aspal karet dengan kualitas terbaik ditunjukkan oleh penurunan penetrasi yang diikuti dengan peningkatan
\end{abstract}


nilai titik lembek, indeks penetrasi dan elastic recovery serta sifat kestabilan aspal karet selama penyimpanan dan akibat pengaruh pemanasan berulang yang relatif baik.

Kata kunci : Aspal karet; kompon karet SIR 20; penetrasi; titik lembek; vulkanisasi

\section{PENDAHULUAN}

Aspal karet merupakan salah satu bentuk aspal modifikasi polimer (Krishnapriya, 2015). Teknologi aspal modifikasi polimer menawarkan keunggulan dalam meningkatkan ketahanan alur (rutting) dan retak panas melintang (thermal cracking) serta menurunkan kerusakan akibat kelelahan (fatique damage), pengelupasan (stripping) dan kepekaan pada suhu dibandingkan dengan aspal murni. Penambahan polimer cenderung meningkatkan kekentalan aspal yang disebabkan oleh mengembangnya (swelling) partikel karet di dalam aspal tersebut. Kekentalan yang tinggi pada aspal modifikasi polimer maka akan berakibat pada meningkatnya kelekatan (adhesive bonding) antara aspal dengan partikel agregat (Malithong \& Thongpin, 2010; Ying \& Rongji, 2010; Shafii et al., 2011).

Karet yang berfungsi sebagai bahan aditif dalam pembuatan aspal karet dapat berasal dari jenis karet mentah seperti lateks pekat maupun karet padat (karet remah SIR 20, karet brown crepe), karet thermoplastik (SBR dan SBS), bahkan dalam bentuk karet serbuk ban bekas (scrap tires) (Wen et al., 2015). Penggunaan karet serbuk ban bekas diperkirakan dapat memberikan solusi atas permasalahan lingkungan karena ban bekas seringkali dianggap sebagai limbah industri sekaligus dapat meningkatkan kinerja aspal sebagai pembentuk lapisan perkerasan jalan dengan mengurangi kebisingan yang ditimbulkan oleh lalu lintas yang padat (Altieb et al., 2016; Sheng et al., 2017; Wang et al., 2017). Namun kompatibilitas yang rendah antara aspal dengan karet serbuk ban menyebabkan kesulitan dalam proses pencampuran serta kestabilan aspal karet selama penyimpanan yang rendah. Saat pengadukan dihentikan, maka antara aspal dan karet serbuk ban akan dengan cepat saling terpisah (Ghaly, 2008).
Penggunaan karet serbuk ban untuk memodifikasi sifat aspal dirasakan kurang sesuai untuk diterapkan di Indonesia, karena tidak sejalan dengan program Pemerintah dalam meningkatkan konsumsi domestik karet mentah sebesar 100 ribu ton/tahun. Indonesia selaku produsen karet alam terbesar kedua dunia, mampu menghasilkan karet TSR termasuk SIR 20 untuk konsumsi ekspor mencapai 2,49 juta ton di tahun 2016 (Gabungan Perusahaan Karet Indonesia [GAPKINDO], 2017). Apabila sebagian produksi karet SIR 20 dapat dimanfaatkan untuk aditif aspal karet maka diperhitungkan dapat menambah serapan domestik karet hingga 60 ribu ton/tahun (Ramadhan et al., 2016).

Karet alam mentah akan menghasilkan aspal karet dengan karakteristik yang berbeda dibandingkan aspal karet berbasis karet serbuk ban. Susunan rantai molekul dalam karet serbuk ban tidak dapat dimodifikasi akibat terbentuknya ikatan silang antar rantai molekul karet yang dijembatani oleh sulfur melalui mekanisme vulkanisasi, sehingga interaksi antara molekul aspal dengan karet hanya terjadi secara fisik. Sementara pada karet mentah, antar rantai panjang molekul karet belum saling membentuk ikatan silang sehingga diharapkan dapat terjalin ikatan kimia yang lebih kuat dibandingkan interaksi fisik antara karet dengan aspal. Interaksi yang terjadi antara aspal dengan karet utamanya difusi fisik (physical diffusion) (Gao \& Cao, 2010). Tipe ikatan atau interaksi antara karet dengan aspal tentu akan berpengaruh terhadap karakteristik aspal karet.

Dalam riset ini akan dipelajari karakteristik aspal karet yang terbuat dari campuran aspal penetrasi (pen) 60 dengan karet mentah dalam bentuk kompon karet sebaagi fungs dari sistem vulkanisasi dan dosis penambahan kompon karet dalam aspal pen 60. Kompon karet merupakan pecampuran bahan kimia karet dalam karet mentah SIR 20. Sedangkan sistem vulkanisasi akan menentukan pembentukan tipe dan jumlah ikatan silang dalam kompon karet tersebut (Ghavibazoo \& Abdelrahman, 2013). 


\section{BAHAN DAN METODE}

Penelitian telah berlangsung di dua lokasi. Lokasi pertama yaitu Pabrik Percobaan dan Laboratorium Penguji Pusat Penelitan Karet untuk kegiatan yang berkaitan dengan persiapan dan pengujian karakteristik vulkanisasi kompon karet. Sementara lokasi kedua berada di Balai Bahan dan Perkerasan Jalan - Puslitbang Jalan dan Jembatan untuk pembuatan dan pengujian aspal karet berbasis kompon karet.

Bahan utama yang digunakan dalam penelitian ini adalah karet alam fasa padat jenis karet remah Standar Indonesian Rubber (SIR 20) dan aspal penetrasi (pen) 60. Sementara bahan pendukung yang digunakan meliputi bahan kimia kompo karet terdiri atas bahan pelunak, bahan pengaktif, bahan antioksidan, bahan pencepat, dan bahan pemvulkanisasi. Selanjutnya alat penelitian mencangkup mesin giling terbuka (two roll open mill) untuk pembuatan kompon karet dan mixer aspal karet.

Pada riset ini, pembuatan kompon karet divariasikan menjadi kompon karet dengan sistem vulkanisasi konvensional (KP1), dan kompon karet dengan sistem vulkanisasi semi effisien (KP2). Kedua sistem vulkanisasi ini dibedakan berdasarkan rasio bahan pencepat terhadap bahan penvulkanisasi yang ditambahkan saat pembuatan kompon karet. Pembuatan kompon karet dalam mesin giling terbuka diawali dengan mastikasi karet SIR20 hingga menjadi plastis. Pada karet yang telah plastis selanjutnya secara berurutan ditambahkan dengan bahan pelunak, bahan pengaktif, bahan antioksidasi, bahan pencepat, dan terakhir bahan pemvulkanisasi. Campuran karet dengan bahan kimia kemudian terus digiling sehingga terbentuk kompon karet padat yang homogen dan siap digunakan sebagai bahan aditif dalam pembuatan aspal karet.

Sebelum dicampurkan dalam aspal pen 60, kompon karet dipotong-potong hingga berukuran kecil (diameter sekitar 3 $\mathrm{mm}$ ). Aspal pen 60 dipanaskan hingga suhu mencapai $150^{\circ} \mathrm{C}$. Untuk tahap pertama pencampuran, pengadukan dilakukan dengan agitator menggunakan blender pemotong dengan lubang yang besar.
Setelah tercapai suhu aspal $150^{\circ} \mathrm{C}$, potongan kompon ditambahkan ke dalam aspal sedikit demi sedikit selama dua menit. Pencampuran dilanjutkan hingga 15 menit. Untuk pencampuran tahap kedua, pengadukan dengan agitator menggunakan blender pemotong dengan lubang kecil pada suhu $150^{\circ} \mathrm{C}$ selama 10 menit.

Penambahan kompon karet padat baik KP1 maupun KP2 dalam aspal pen 60 divariasikan pada dosis $3 \%, 5 \%, 7 \%$ dan $9 \%$. Selanjutnya untuk mengetahui kondisi optimal pencampuran juga dilakukan uji coba pencampuran kompon karet alam KP1 sebesar $5 \%$ ke dalam aspal pen 60 pada berbagai kecepatan putaran mesin agitator yaitu $1000 \mathrm{rpm}, 2000 \mathrm{rpm}, 4000 \mathrm{rpm}, 6000$ rpm, 8000 rpm, dan 10000 rpm. Penentuan kondisi optimal pencampuran didasarkan kepada pengujian karakteristik aspal karet dan uji pemisahan karet alam dari aspal karet secara ekstrasi refluk dengan solven benzena.

\section{HASIL DAN PEMBAHASAN}

\section{Karakteristik Vulkanisasi Kompon Karet}

Karakteristik vulkanisasi dapat digunakan untuk memprediksi sifat fisik produk karet yang dihasilkan. Nilai karakteristik vulkanisasi kompon karet sangat bergantung pada sistem vulkanisasi kompon yang digunakan. Sistem vulkanisasi konvensional akan menghasilkan derajat ikatan silang antar molekul karet yang dijembatani oleh sulfur yang lebih tinggi dibandingkan dengan sistem vulkanisasi semi effisien. Hal ini dikarenakan jumlah bahan pemvulkanisasi (sulfur) yang ditambahkan dalam sistem vulkanisasi konvensional jauh lebih tinggi daripada sistem vulkanisasi semi effisien. Nilai derajat ikatan silang dalam karakteristik vulkanisasi digambarkan oleh nilai delta torsi.

Sebaliknya sistem vulkanisasi semi effisien memberikan waktu vulkanisasi yang lebih cepat karena pada sistem ini menggunakan komposisi bahan pencepat yang lebih banyak daripada komposisi bahan pemvulkanisasi. Meskipun memiliki derajat ikatan silang yang lebih tinggi, namun pada umumnya produk karet yang diolah dari kompon karet dengan sistem 
vulkanisasi konvensional tidak tahan terhadap pengusangan (ageing) karena pada sistem vulkanisasi ini banyak terbentuk ikatan disulfida atau polisulfida yang mudah terurai karena pengaruh panas. Sedangkan dengan sistem semi effisien cenderung lebih tahan terhadap pengusangan karena ikatan silang yang terbentuk mayoritas dijembatani oleh ikatan monosulfida yang tahan terhadap panas.

Dengan derajat ikatan silang yang tinggi diharapkan dapat memberikan sifat elastis yang baik terhadap aspal karet. Sementara dengan ketahanan pengusangan yang baik diharapkan dapat turut berkonstribusi dalam memperlama umur pakai aspal karet.

\section{Korelasi Kecepatan Putaran Mesin Agitator dengan Sifat Fisik Aspal Karet}

Homogenitas aspal karet atau penyebaran karet alam dalam aspal karet sangat dipengaruhi oleh kecepatan putaran mesin agitator serta kekentalan aspal pen 60 yang bergantung pada suhu pemanasan saat pencampuran. Mengacu pada Gambar 1 terlihat bahwa perubahan pengaturan kecepatan putaran mesin agitator diikuti dengan perubahan sifat fisik aspal karet. Dengan bertambahnya kecepatan putaran mesin agitator maka kekerasan aspal karet meningkat, yang digambarkan oleh penurunan nilai penetrasi yang semula sebesar $59 \mathrm{dmm}$ (pada $1000 \mathrm{rpm}$ ) menjadi 54 dmm (pada $10000 \mathrm{rpm}$ ). Penurunan nilai penetrasi diperkirakan disebabkan karena semakin cepat putaran mesin agitator maka dispersi kompon karet alam dalam aspal pen 60 semakin baik.

Kecepatan putaran mesin turut berpengaruh terhadap nilai titik lembek, yang pada awalnya pada $1000 \mathrm{rpm}$ sebesar $49,3^{\circ} \mathrm{C}$ menjadi $52,8^{\circ} \mathrm{C}$ pada $10000 \mathrm{rpm}$. Peningkatan nilai titik lembek terbesar terjadi pada putaran $1000 \mathrm{rpm}$ hingga 6000 rpm yang mencapai $3,1^{\circ} \mathrm{C}$, sedangkan dari putaran $6000 \mathrm{rpm}$ sampai dengan 10000 rpm pola perubahan nilai titik lembek hanya sedikit bahkan mendekati mendatar sebesar $0,4^{\circ} \mathrm{C}$. Seiring dengan nilai titik lembek, butiran kompon karet alam yang terekstrak juga mengalami peningkatan. Peningkatan terbesar terjadi antara putaran $2000 \mathrm{rpm}$ hingga $6000 \mathrm{rpm}$ yang semula 40,3\% pada $2000 \mathrm{rpm}$ menjadi $98 \%$ pada $6000 \mathrm{rpm}$. Hal ini terjadi karena pada kecepatan putaran mesin agitator yang semakin tinggi maka butiran kompon karet menjadi semakin halus sehingga banyak yang terekstrasi oleh solven benzena.

Berdasarkan hasil percobaan ini serta dengan mempertimbangkan pengaruh terhadap sifat fisik aspal karet maka kecepatan agitator untuk pencampuran selanjutnya (kompon KP2) hanya menggunakan kecepatan putaran pada $6000 \mathrm{rpm}$.

Tabel 1. Karakteristik vulkanisasi kompon karet

Table 1. Curing characteristic of natural rubber compound

\begin{tabular}{llcc}
\hline \multirow{2}{*}{ No } & \multicolumn{1}{c}{$\begin{array}{c}\text { Parameter } \\
\text { Parameters }\end{array}$} & \multicolumn{2}{c}{ Nilai } \\
\cline { 3 - 4 } & \multicolumn{1}{c}{ Kalue } \\
\hline 1 & Waktu, menit & 20,6 & KP 2 \\
2 & Suhu, ${ }^{\circ}$ C & 140 & 20,4 \\
3 & Torsi maksimum, Kg -cm & 6,85 & 140 \\
4 & Torsi minimum, Kg -cm & 0,31 & 5,69 \\
5 & Delta torsi, Kg -cm & 6,54 & 0,63 \\
6 & Waktu vulkanisasi, min:sec & 7,14 & 5,06 \\
7 & Waktu pra vulkanisasi, min:sec & 4,33 & 9,07 \\
\hline
\end{tabular}




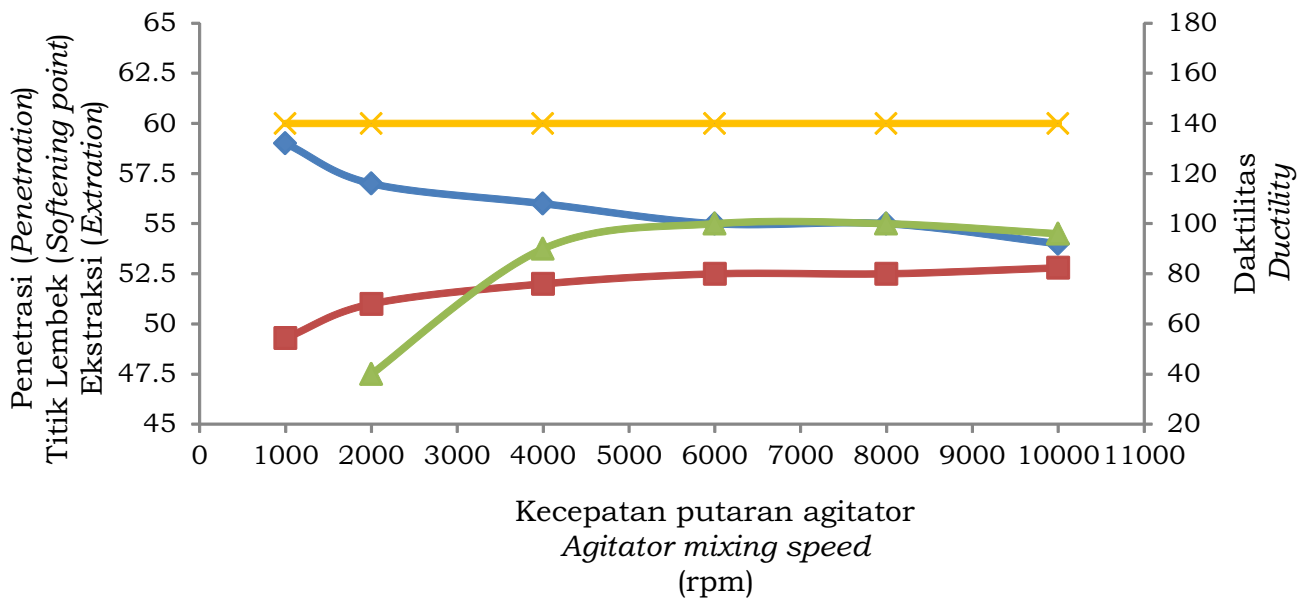

$\leadsto$ Penetrasi $0,1 \mathrm{~mm} \curvearrowleft$ Ttk Lembek ${ }^{\circ} \mathrm{C} \leadsto$ Ekstraksi $\leftarrow$ Daktilitas $\mathrm{cm}$

Gambar 1. Korelasi kecepatan agitator terhadap sifat fisik aspal karet dengan penambahan $5 \%$ kompon karet

Figure 1. Correlation between agitator speed to physical properties of rubberized asphalt with addition of $5 \%$ rubber compound

\section{Sifat Fisik Aspal Karet Berbasis Kompon Karet Tanpa Bahan Pengisi}

Hasil pengujian sifat fisik aspal karet yang terbuat dari campuran aspal pen 60 dengan kompon karet konvensional KP1 disajikan dalam Tabel 2. Sedangkan Tabel 3 merangkum hasil pengujian aspal karet dari penambahan kompon karet semi effisien KP2 ke dalam aspal pen 60. Dari Tabel 2 dan Tabel 3 terlihat bahwa penambahan kompon karet ke dalam aspal pen 60 meningkatkan kekerasan aspal yang ditunjukkan dengan penurunan nilai penetrasi aspal karet. Pada dosis penambahan kompon karet yang sama ke dalam aspal pen 60, kompon karet semi effisien KP2 cenderung membentuk aspal karet yang lebih keras daripada kompon karet konvensional KP1. Semakin banyak jumlah kompon karet maka akan semakin keras aspal karet yang dihasilkan akibat dari semakin banyak komponen polimer karet rantai panjang yang tersebar dalam matriks aspal sehingga turut berkonstribusi terhadap naiknya bobot molekul aspal karet. Peningkatan kekerasan aspal karet diikuti dengan semakin tingginya titik lembek serta menurunnya daktilitas aspal karet (Owaid, 2014).
Parameter indeks penetrasi mengindikasikan kepekaan aspal terhadap suhu. Aspal termasuk dalam golongan material yang bersifat termoplastik yaitu dapat berubah fasa bergantung pada perubahan suhu, apabila suhu naik akibat pemanasan aspal akan menjadi lunak dan akan mengeras ketika suhu diturunkan. Oleh karena itu, semakin tinggi nilai indeks penetrasi aspal maka mengakibatkan aspal menjadi semakin tahan terhadap perubahan suhu. Dengan demikian diharapkan pada saat aspal digunakan sebagai pembentuk lapisan perkerasan jalan, aspal tersebut tidak akan menjadi rapuh pada kondisi suhu rendah dan tidak terlampau plastis ketika suhu tinggi (Pradani, 2013).

Penambahan kompon karet KPI dan KP2 dalam aspal pen 60 terbukti menaikkan nilai indeks penetrasi aspal karet, dengan pengaruh kinerja KP2 yang lebih baik daripada KP1. Kompon karet KP2 yang didesain dengan sistem vulkanisasi semi effisien diketahui memiliki sifat ketahanan terhadap panas yang lebih unggul dibandingkan kompon karet KP1 yang dirancang dengan sistem vulkanisasi konvensional. Dalam KP2 banyak terbentuk ikatan monosulfida dalam jaringan tiga 
Tabel 2. Sifat fisik aspal karet dengan penambahan kompon KP1 Table 2. Physical properties of rubberized asphalt based on KP1 compound

\begin{tabular}{|c|c|c|c|c|c|}
\hline \multirow[t]{2}{*}{$\begin{array}{l}\text { Parameter } \\
\text { Parameters }\end{array}$} & \multirow{2}{*}{$\begin{array}{l}\text { Aspal } \\
\text { murni } \\
\text { Pure } \\
\text { asphalt }\end{array}$} & \multicolumn{4}{|c|}{$\begin{array}{c}\text { Dosis penambahan KP1 } \\
\text { KP1 additional dosage } \\
(\%)\end{array}$} \\
\hline & & 3 & 5 & 7 & 9 \\
\hline Penetrasi, $\mathrm{mm}$ & 63 & 55 & 55 & 54 & 53 \\
\hline Daktilitas, cm & 140 & 140 & 140 & 74 & 31 \\
\hline Titik lembek, ${ }^{\circ} \mathrm{C}$ & 49,2 & 51,3 & 52,4 & 55,7 & 57,2 \\
\hline Indeks penetrasi & $-0,86$ & $-0,69$ & $-0,37$ & 0,33 & 0,57 \\
\hline Kehilangan berat dengan TFOT, \% asli & 0,0292 & 0,0290 & 0,0078 & 0,0048 & 0,0030 \\
\hline Penetrasi setelah TFOT, \% asli & 81 & 96 & 94 & 95 & 97 \\
\hline Titik lembek setelah TFOT, ${ }^{\circ} \mathrm{C}$ & 51,6 & 53,1 & 53,4 & 53,7 & 54,0 \\
\hline Daktilitas setelah TFOT, $\mathrm{cm}$ & $>140$ & $>140$ & $>140$ & $>140$ & $>140$ \\
\hline Keelastisan setelah pengembalian, $\%$ & - & 7,5 & 10,0 & 12,5 & 28,8 \\
\hline \multicolumn{4}{|c|}{ Perbedaan penetrasi setelah penyimpanan pada suhu 163} & \multicolumn{2}{|l|}{${ }^{0} \mathrm{C}$} \\
\hline Langsung, $0,1 \mathrm{~mm}$ & & 0,6 & 2,8 & 3,6 & 3,4 \\
\hline $1 \times 24$ jam, $0,1 \mathrm{~mm}$ & & 1,2 & 4,4 & 55,8 & 35,6 \\
\hline $2 \times 24$ jam, $0,1 \mathrm{~mm}$ & & 2,4 & 19,2 & 51,6 & 32,8 \\
\hline $5 \times 24$ jam, $0,1 \mathrm{~mm}$ & & 0,0 & 21,8 & 68,0 & 64,8 \\
\hline \multicolumn{4}{|c|}{ Perbedaan titik lembek setelah penyimpanan pada suhu 16} & ${ }^{0} \mathrm{C}$ & \\
\hline Langsung, ${ }^{\circ} \mathrm{C}$ & & 0,5 & 0,3 & 0,9 & 0,6 \\
\hline $1 \times 24$ jam, ${ }^{\circ} \mathrm{C}$ & & 0,1 & 0,2 & 2,1 & 0,5 \\
\hline $2 \times 24$ jam, ${ }^{\circ} \mathrm{C}$ & & 2,0 & 0,9 & 2,4 & 1,7 \\
\hline $5 \times 24$ jam, ${ }^{\circ} \mathrm{C}$ & & 0,1 & 1,0 & 6,0 & 2,6 \\
\hline
\end{tabular}

Tabel 3. Sifat fisik aspal karet dengan penambahan kompon KP2 Table 3. Physical properties of rubberized asphalt based on KP2 compound

\begin{tabular}{|c|c|c|c|c|c|}
\hline \multirow[t]{2}{*}{$\begin{array}{l}\text { Parameter } \\
\text { Parameters }\end{array}$} & \multirow{2}{*}{$\begin{array}{l}\text { Aspal } \\
\text { murni } \\
\text { Pure } \\
\text { asphalt }\end{array}$} & \multicolumn{4}{|c|}{$\begin{array}{c}\text { Dosis penambahan KP2 } \\
\text { KP2 additional dosage } \\
(\%)\end{array}$} \\
\hline & & 3 & 5 & 7 & 9 \\
\hline Penetrasi, $\mathrm{mm}$ & 63 & 51 & 51 & 50 & 46 \\
\hline Daktilitas, $\mathrm{cm}$ & 140 & 140 & 140 & 135 & 58 \\
\hline Titik lembek, ${ }^{\circ} \mathrm{C}$ & 49,2 & 53,5 & 54,5 & 57,4 & 60,0 \\
\hline Indeks penetrasi & $-0,86$ & $-0,32$ & $-0,12$ & 0,50 & 0,80 \\
\hline Kehilangan berat dengan TFOT, \% asli & 0,0292 & 0,0045 & 0,0129 & 0,0088 & 0,0093 \\
\hline Penetrasi setelah TFOT, \% asli & 81 & 102 & 102 & 101 & 104 \\
\hline Titik lembek setelah TFOT, ${ }^{\circ} \mathrm{C}$ & 51,6 & 51,6 & 52,3 & 52,8 & 54,3 \\
\hline Daktilitas setelah TFOT, cm & $>140$ & $>140$ & $>140$ & $>140$ & $>140$ \\
\hline Keelastisan setelah pengembalian, \% & - & 8,0 & 10,0 & 12,5 & 23,8 \\
\hline \multicolumn{6}{|c|}{ Perbedaan penetrasi setelah penyimpanan pada suhu $163{ }^{\circ} \mathrm{C}$} \\
\hline Langsung, $0,1 \mathrm{~mm}$ & & 0,2 & 0,4 & 0,2 & 0,2 \\
\hline $1 \times 24$ jam, $0,1 \mathrm{~mm}$ & & 3,2 & 7,0 & 11,4 & 62,0 \\
\hline $2 \times 24$ jam, $0,1 \mathrm{~mm}$ & & 1,4 & 10,4 & 40,0 & 91,8 \\
\hline $5 \times 24$ jam, $0,1 \mathrm{~mm}$ & & 5,2 & 15,2 & 59,6 & 60,6 \\
\hline \multicolumn{6}{|c|}{ Perbedaan titik lembek setelah penyimpanan pada suhu 163} \\
\hline Langsung, ${ }^{\circ} \mathrm{C}$ & & 0,2 & 0,2 & 0,5 & 0,6 \\
\hline $1 \times 24 \mathrm{jam}^{\circ}{ }^{\circ} \mathrm{C}$ & & 0,2 & 0,9 & 1,1 & 2,9 \\
\hline $2 \times 24$ jam, ${ }^{\circ} \mathrm{C}$ & & 0,7 & 1,2 & 1,5 & 3,0 \\
\hline $5 \times 24$ jam, ${ }^{\circ} \mathrm{C}$ & & 0,3 & 0,4 & 2,4 & 5,1 \\
\hline
\end{tabular}


dimensi antar molekul karet yang dijembatani oleh sulfur. Ikatan monosulfida tidak mudah terdekomposisi akibat pengaruh panas, sedangkan dalam kompon karet KP1 ikatan polisulfida yang cepat terurai karena pengaruh panas lebih mendominasi dalam struktur jaringan tiga dimensi antara molekul karet. Keunggulan kompon karet KP2 tersebut yang turut berkonstribusi dalam meningkatkan ketahanan aspal karet terhadap perubahan suhu.

Pengujian Thin Film Oven Test (TFOT) dimaksudkan untuk mengetahui durabilitas aspal karet akibat proses pemanasan berulang sekaligus mengetahui ketahanan aspal karet terhadap pengusangan. Uji TFOF difokuskan pada parameter utama sifat aspal yaitu penetrasi, titik lembek, daktilitas dan kehilangan berat. Penambahan kompon karet sebagai aditif menurunkan kehilangan berat setelah TFOT pada aspal karet. Demikian pula dengan nilai penetrasi dan titik lembek, sementara nilai daktilitas cenderung konstan. Altieb et al. (2016) menyatakan bahwa nilai penetrasi yang dianjurkan untuk aspal polimer setelah pengujian TFOT minimum sebesar 65\%, sedangkan selisih nilai titik lembek yang diizinkan sebesar $1-2^{\circ} \mathrm{C}$ atau tidak diperkenankan melebihi $5^{\circ} \mathrm{C}$. Berdasarkan data hasil pengujian terlihat bahwa aspal karet dengan penambahan kompon karet KP1 maupun KP2 memenuhi persyaratan tersebut. Aspal karet dengan penambahan kompon karet KP1 memiliki nilai penetrasi setelah TFOT yanng lebih rendah daripada aspal karet dengan penambahan kompon karet KP2 yang berarti bahwa aspal karet dengan penambahan kompon karet KP1 lebih keras setelah mengalami pemanasan berulang. Sifat ini diperkirakan akibat dari terjadinya reaksi vulkanisasi lanjut kompon karet KP1 yang telah bercampur dalam aspal pen 60 ketika aspal karet tersebut dipanaskan akibat konsentrasi sulfur yang berlebih dalam formula kompon KP1. Reaksi vulkanisasi lanjut meningkatkan derajat ikatan silang antar molekul karet yang turut meningkatkan kekerasan aspal karet. Selain itu bertambahnya derajat ikatan silang antar molekul karet juga berakibat pada meningkatnya keelastisan setelah pengembalian (elastic recovery) aspal karet.
Untuk mengetahui kestabilan aspal karet yang terbuat dari campuran aspal pen 60 dengan kompon karet KP1 dan KP2 terhadap durasi penyimpan maka dilakukan pengamatan parameter penetrasi dan titik lembek pada berbagai waktu penyimpanan pada suhu $163^{\circ} \mathrm{C}$. Hasil pengukuran disajikan dalam Tabel 2 untuk aspal karet dengan pencampuran kompon karet KP1 dan Tabel 3 untuk aspal karet dengan penambahan kompon karet KP2. Dari kedua tabel tersebut diketahui bahwa pada waktu simpan yang sama, semakin tinggi dosis kompon karet yang ditambahkan maka meningkatkan sifat fisik aspal karet. Pengaruh terhadap nilai penetrasi lebih signifikan daripada titik lembek. Selanjutnya pada konsentrasi penambahan kompon karet yang sama, dengan durasi penyimpanan yang bertambah terlihat bahwa perubahan sifat fisik aspal karet tidak terlalu signifikan atau aspal karet relatif stabil selama masa penyimpanan. Kestabilan aspal karet tersebut diketahui berdasarkan perbedaan nilai titik lembek aspal yang kurang dari $2^{\circ} \mathrm{C}$.

\section{KESIMPULAN}

Kesimpulan yang dapat ditarik berdasarkan hasil eksperimen dan pengujian adalah bahwa proses pencampuran kompon karet ke dalam aspal panas dalam pembuatan aspal karet sangat bergantung kepada suhu dan waktu pencampuran serta kecepatan putaran mesin agitator. Kecepatan putaran mesin agitator yang optimal diketahui tercapai pada $6000 \mathrm{rpm}$ untuk kondisi penambahan kompon karet sebesar $5 \%$, pada suhu $150^{\circ} \mathrm{C}$. Selanjutnya berdasarkan hasil karakterisasi sifat fisik aspal karet diperoleh bahwa kompon karet SIR 20 yang dihasilkan dari sistem vulkanisasi semi effisien (KP2) dengan dosis 5-7\% dapat membentuk aspal karet dengan kualitas terbaik yang ditunjukkan dengan penurunan nilai penetrasi dari $63 \mathrm{~mm}$ menjadi $50-51 \mathrm{~mm}$ yang mengindikasikan peningkatan kekerasan aspal karet, yang diikuti oleh peningkatan nilai titik lembek dari $49,2^{\circ} \mathrm{C}$ menjadi 54,5 dan $57,4^{\circ} \mathrm{C}$. 


\section{DAFTAR PUSTAKA}

Altieb, Z.A., Aziz, M.M.A., Kassim, K.A.B., \& Jibrin, H.B. (2016). A short review on using crumb rubber as modification of bitumen binder. Jurnal Teknologi, 78, 29-36.

Gabungan Perusahaan Karet Indonesia. (2017). Statistik ekspor karet alam Indonesia berdasarkan jenis mutu. Jakarta, Indonesia : GAPKINDO.

Gao, Y., \& Cao, R. (2010). Interaction theory of asphalt and rubber. Journal of Wuhan University of Technology-Mater. Sci. 25(5), 853-855. Doi: $10.1007 / \mathrm{s} 11595-010-0107-y$.

Ghaly, N.F. (2008). Effect of sulfur on the storage stability of the tire rubber modified asphalt. World Journal of Chemistry, 3(2), 42-50.

Ghavibazoo A., \& Abdelrahman, M. (2013). Composition analysis of crumb rubber during interaction with asphalt and effect on properties of binder. International Journal of Pavement Engineering, 14(5), 517-530. Doi : 10.1080/10298436.2012.721548.

Krishnapriya, M.G. (2015). Performance evaluation of natural rubber modified bituminous mixes. Journal of Civil, Structural, Enviromental, Water Resources and Infrastructure Engineering Research, 5(1), 1-12.

Malithong, S., \& Thongpin, C. (2010). The modification of asphalt emulsion using pre-vulcanized natural rubber rubber latex for highway application. Advanced Material Research, 93-94, $639-642$. D o i : 10.4028/www.scientific.net/AMR.9394.639

Owaid, K.A. Effect of aging on the rheological properties of the modified asphaltrubber system using microwave technique. European Chemistry Bulletin, 3(7), 668-671. Doi: 10.17628/ECB.2014.3.668.
Pradani, N. (2013). Pengaruh penambahan polimer elastomer terhadap indeks penetrasi aspal yang mengandung aspal daur ulang. Infrastruktur, 3(1), 915.

Ramadhan, A., Cifriadi, A., Prastanto, H., Puspitasari, S., Falaah, S.F., \& Maspanger, D.R. (2017). The role of IRRI in developing natural rubber goods as supporting materials for the national infrastructure project. Proceedings of the International Rubber Conference 2017 (p. 714-729). Jakarta, Indonesia : IRRI-IRRDB.

Shafii, M.A., Rahman, M.Y.A., \& Ahmad, J. (2011). Polymer modified asphalt emulsion. International Journal of Civil \& Enviromental Engineering, 11(6), 4349.

Sheng, Y., Li, H., Geng, J., Tian, Y., Li, Z., \& Xiong, R. (2017). Production and performance of desulfurized rubber asphalt binder. International Journal of Pavement Research and Technology, 10, 262-273. Doi : 10.1016/j.ijprt. 2017.02.002.

Wang, T., Xiao, F., Amirkhanian, S., Huang, W., \& Zheng, M. (2017). A review on low temperature performances of rubberized asphalt materials. Construction and Building Materials, 145, 483-505. Doi : 10.1016/j. conbuildmat.2017.04.031.

Wen, Y., Wang, Y., Zhao, K., \& Sumalee, A. (2015). The use of natural rubber latex as a renewable and sustainable modifier of asphalt binder. International Journal of Pavement Engineering, 2015, 1-13. Doi : 10.1080 / 10298436.2015 .1095913$.

Ying, G., \& Rongji, C. (2010). Interaction theory of asphalt and rubber. Journal of Wuhan University of TechnologyMater. Sci. Ed, 25(5), 853-855. Doi : $10.1007 / \mathrm{s} 11595-010-0107-y$. 